\title{
Compensation of mass spectrometric interferences with the miniRUEDI portable mass spectrometer
}

\author{
M.S. BRENNWALD ${ }^{1 *}$, Y. TOMONAGA $^{1}$, R. KIPFER ${ }^{1,2}$
}

${ }^{1}$ Eawag, Swiss Federal Institute of Aquatic Science and Technology, Dept. Water Resources and Drinking Water ${ }^{2}$ Swiss Federal Institute of Technology in Zurich, Dept. of

Environmental Systems Science and Dept. of Earth Sciences

The miniRUEDI is a portable mass spectrometer system, which is widely used in environmental research ${ }^{1,2}$ to study biogeochemical turnover and the origin, mixing and exchange of fluids. The miniRUEDI instruments are designed for on-site gas analysis during field work at remote locations and allow quantification of individual gas species in gaseous or aqueous matrices. The partial pressures of the gas species in a sample (e.g., $\mathrm{He}, \mathrm{Ar}, \mathrm{Kr}$, $\mathrm{N}_{2}, \mathrm{O}_{2}, \mathrm{CO}_{2}, \mathrm{CH}_{4}$, etc.) are calibrated by comparison of the ion-current peak-heights measured with the mass spectrometer relative to a reference gas with well known partial pressures.

However, depending on the target species and the composition of the analyzed gases, some ion-current peaks may result from overlapping signals from different species contributing to the ion-current at the same $\mathrm{m} / \mathrm{z}$ ratio (e.g. $\mathrm{CH}_{4} / \mathrm{O}_{2} / \mathrm{N}_{2}$ or $\mathrm{Ne} / \mathrm{Ar} / \mathrm{H}_{2} \mathrm{O}$ ). Such interferences need to be disentangled and compensated to allow accurate calibration of the gas partial pressures by ion-current peakheight comparison. To this end, we developed a tool for accurate compensation of mass spectrometric interferences. This tool deconvolves the measured ion-current spectra in terms of well-known spectra of the involved gas species. The deconvolution yields the fractions of the ion-current contributions of the various gas species to a given ioncurrent peak and thereby accomplishes a substantial improvement of the analytical accuracy in situations where mass-spectrometric interferences cannot be avoided.

(1) Brennwald et al. (2016), Environ. Sci. Technol. 50, 24, 1345513463, DOI: 10.1021/acs.est.6b03669

(2) Gasometrix GmbH, Switzerland (www.gasometrix.com) 